\title{
The Models of Sectors' Investment restructuring
}

\author{
Kan Liu ${ }^{1}$ \\ ${ }^{1}$.School of Management, Harbin University of commerce, Harbin150028, China
}

\begin{abstract}
Adjusting the investment proportion of each sub-industry, can promote the evolution of industrial structure, and realize the optimization of industrial structure. Based on the input-output theory, the model of investment sector restructuring affection on output is built to provide insights into the input-output mechanisms how the sectors output are affected by the transfer of investment in the sector. According to the study, the effect of investment sector restructuring on the industry or industries, are closely related to the production direct consumption coefficient, investment direct consumption coefficient, and total investment.
\end{abstract}

Keywords: Investment structure; Inputoutput; Sector output; Model

\section{Introduction}

The investment sector restructuring refers to the adjustment of investment funds ratio between various departments, compared to the investment industry structure focused on three industrial structure, which has more detailed description of the investment proportion of each sub-industry. Adjustment of investment structure will promote the evolution of industrial structure, and can realize the changes and optimization of economic structure. It also can promote the labor, capital and resources to flow from the demand shrinking sectors to the demand expanding sectors, from the labor- intensive sectors to capital-intensive sectors, and from small value-added primary processing sector to value added manufacturing sector, which can contribute to a country's economic (Liu Yu, $2005)^{[1]}$. Therefore, the development of the industrial structure depends on the adjustment of investment in sectors. Finding the impact of investment structural adjustment on China's economic and industries, can help to develop a reasonable and effective strategy of investment sectors restructuring, and can realize the goal of China's economic development and industrial restructure.

Many scholars have recognized the importance of investment restructuring ${ }^{[2]}$, quantitative research focused on three industries, the investment restructuring of more sectors mostly focus on qualitative research. The studies contributed to the quantitative research of investment structure adjustment, but limited to the technical means and methods of statistical econometric analysis, mainly based on historical data analysis. On one hand, the prediction and inference can not completely ignore some analytical error caused by the roughness, ambiguity and uncertainty. On the other hand, the current study can only solve the issues of three industrial investment adjustments, and there isn't quantitative study according to sectors investment restructuring. 


\section{The Models of Sectors' Investment restructuring}

\subsection{The master equation}

Leontief static input-output model:

$$
X(t)=A X(t)+Y(t)
$$

Plus :A= $\left(a_{i j}(t)\right)_{n \times n}$ is the direct consumption coefficient matrix, and is called production direct consumption coefficient matrix in this paper for distinction; $X(t)=\left[x_{1}(t), \ldots, x_{n}(t)\right]^{T}$ is the industry output vector; $\mathrm{Y}(\mathrm{t})$ is the final product vector, which can be divided into investment goods vector $\mathrm{Y}^{I}(\mathrm{t})$, consumer goods vector $\mathrm{Y}^{C}(\mathrm{t})$, the export vector $\mathrm{Y}^{0}(\mathrm{t})$ and import vector $\mathrm{Y}^{E}(\mathrm{t})$. So that Leontief static inputoutput model can be expressed as:

$$
X(t)=A X(t)+Y^{C}(t)+Y^{I}(t)+Y^{0}(t)-Y^{E}(t)
$$

Let $y^{I}(t)$ be the total amount of investment. Introduce the investment vector $I(t)$ as the investment of the various industrial sectors in year $t$; let $D=\left(d_{1}, d_{2} \ldots, d_{n}\right)$ be representative of the investment structure, reflecting the ratio between the various departments in the total investment in the whole society in the national economy. So $I(t)=D y^{I}(t)$.

Let $G=\left(g_{i j}\right)$, on behalf of investors direct consumption coefficient matrix, similar to the principle of production direct consumption coefficient matrix $(\boldsymbol{A})$, which reflects how many consumption of sector $i$ 's product can form per unit of capital of sector $j$, is a more important indicators in this article ${ }^{[3]}$. Establish the links of investment goods vector $Y^{I}(t)$ and investment vector $I(t)$, $Y^{I}(t)=G I(t)$.

$$
G=\left(\begin{array}{cccc}
g_{11} & g_{12} & \cdots & g_{1 n} \\
g_{21} & g_{22} & \cdots & g_{2 n} \\
\vdots & \vdots & \ddots & \vdots \\
g_{n 1} & g_{n 2} & \cdots & g_{n n}
\end{array}\right), \quad \sum_{i=1}^{n} g_{i j}=1, j=1, \cdots, n
$$

Therefore, the relation equation of investment goods $Y^{I}(t)$, with a total in- vestment $y^{I}(\mathrm{t})$, the investment structure $D$, investment direct consumption coefficient matrix $G$, can be set up as(3).

$$
Y^{I}(t)=G D y^{I}(\mathrm{t})
$$

Put (3) into the Leontief inputoutput model, get the master equation:

$$
X(t)=A X(t)+G D y^{I}(t)+Y^{C}(t)+Y^{O}(t)-Y^{E}(t)
$$

\subsection{The model of investment struc- tural adjustment}

Merge the vetors which are weakly associated with the adjustment of investment structure into $M(\mathrm{t})$ in the master equation, such as consumer vector $Y^{C}(t)$, export vector $Y^{0}(t)$, and import vector $Y^{E}(t)$. So (4) can be simplified to the relationship equation between the structure of investment:

$$
(I-A) X(t)=G D y^{I}(t)+M(t)
$$

In the steady economic growth system, the total investment, is mainly affected by the income level, the bank rate, the marginal effect of capital and national policies ${ }^{[4]}$,independent of the investment structure, so it is constant in this study, which can help to focus on mechanism that the adjustment of investments in various industries affects the industry. To simplify the research process, the industrial sector is transferred into a two-sector inputoutput structure. Let $k$ industry or $k$ industries as the research object, the original investment ratio is $d_{k}$, the investment ratio is adjusted $\Delta d$, so the investment ratio becomes $d_{k}+\Delta d$; the remaining units are merged into sector $p$, after the investment structure adjustment, the ratio of investment is turned from $d_{p}$ into $d_{p}-\Delta d$. At this point, the parameters of the two departments $(k, p)$ are as follows:

Two-sector production structure: $X(t)=\left(\begin{array}{l}x_{k} \\ x_{p}\end{array}\right), x_{k}$ means the total industrial 
output of $k$ industry or industries; $x_{p}$ means the total industrial output of $p$ industry or industries.

Production direct consumption coefficient $A=\left(\begin{array}{ll}a_{k k} & a_{k p} \\ a_{p k} & a_{p p}\end{array}\right), a_{i j}$ means the consumption of $i$ industry that per unit output of $j$ sectors, $(i=p, k ; j=p, k)$. Investment direct consumption coefficient: $G=\left(\begin{array}{ll}g_{k k} & g_{k p} \\ g_{p k} & g_{p p}\end{array}\right) ; g_{i j}$ means the consumption of $i$ industry that per unit investment of $j$ sectors, $(i=p, k ; j=p, k)$. Investment structure $^{D=}\left(\begin{array}{l}d_{k}+\Delta d \\ d_{p}-\Delta d\end{array}\right) ; d_{k}+d_{p}=1$.

Put these economic variables into formula(5),then there is:

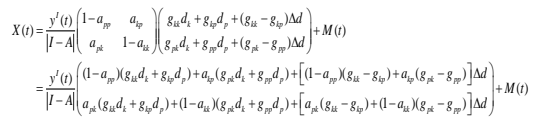

Thus, the amount of output affected by adjusting the investment structure is:

$$
\begin{aligned}
\Delta X(t) & =\frac{y^{I}(t) \Delta d}{|I-A|}\left(\begin{array}{cc}
1-a_{p p} & a_{k p} \\
a_{p k} & 1-a_{k k}
\end{array}\right)\left(\begin{array}{c}
g_{k k}-g_{k p} \\
g_{p k}-g_{p p}
\end{array}\right) \\
& =\frac{y^{I}(t) \Delta d}{|I-A|}\left(\begin{array}{l}
\left.1-a_{p p}\right)\left(g_{k k}-g_{k p}\right)+a_{k p}\left(g_{p k}-g_{p p}\right) \\
a_{p k}\left(g_{k k}-g_{k p}\right)+\left(1-a_{k k}\right)\left(g_{p k}-g_{p p}\right)
\end{array}\right)
\end{aligned}
$$

Since $g_{k k}+g_{p k}=1, g_{k p}+g_{p p}=1$, the formula can be transferred further into:

$$
\Delta X(t)=\left(\begin{array}{c}
\Delta x_{k} \\
\Delta x_{p}
\end{array}\right)=\frac{y^{I}(t) \Delta d}{|I-A|}\left(\begin{array}{c}
\left(1-a_{p p}-a_{k p}\right)\left(g_{k k}-g_{k p}\right) \\
\left(1-a_{k k}-a_{p k}\right)\left(g_{p k}-g_{p p}\right)
\end{array}\right)
$$

Equation (7) is called the output effects model of investment structural adjustment, representing the range and scope that adjusting ratio of an industry or multiple industries investment affects the output of the sector and other sectors, as well as the role and influence content of total investment, the Industrial production direct consumption coefficient and investment direct consumption coefficient in the whole process.

\section{The analysis of the role of invest- ment structural adjustment on the sector output}

\subsection{The direction of the industry output changes}

Since $1-a_{k p}-a_{p p}>0$, so the direction of the output change casused by the investment ratio adjustment depends on the relationship between $g_{k k}$ and $g_{k p}$. If $g_{k k}>g_{k p}$, per unit of capital formation of the $k$ industry or $k$ industries will boost more output of it's own than other industries, so the proportion of investment and output change in the same direction, and increasing the proportion of investment in this sector can achieve the promotion of the sector output, as well as inhibiting the output of other industries; By the same rule, reducing the proportion of investment in this sector will inhibit the production of the sector and promote the output of other sectors. If $g_{k k}<g_{k p}$, per unit of capital formation of the $k$ industry or $k$ industries will boost less output of its own than other industries, there will be a reverse effect that the sector output will decrease with the increasing of investment in the sector while other sectors has the output increased.

\subsection{Industrial output volatility.}

Volatility of changes in industrial output depends on other economic indicators and their relationship, such as the production direct consumption coefficient,investment direct consumption coefficient, total investment, and the investment structure adjustment. First, the impact on output is proportional with the adjustment of investment structure and investment adjustment amount. The main factors which lead to output volatility are $\left(1-a_{k p}-a_{p p}\right)$ and $\left|g_{k k}-g_{k p}\right|$ (absolute). For $k$ industries or $k$ industry groups, $\left(1-a_{k p}-a_{p p}\right)$ reflects the valueadded input that other departments re- 
quired to produce one unit of total product, the greater the volume is, the smaller the adjustment will impact the output of $k ;\left|g_{k k}-g_{k p}\right|$ reflects the difference between the contribution of $k$ 's output to per unit of capital formation of $k$ and other industries, and the greater its value is, the greater the impact of the investment adjustment on $k$ 's output.

\subsection{Changes in the total output of industry}

While the adjustment proportion of $k$ industrial investment is $\Delta d$, the total output will change as below:

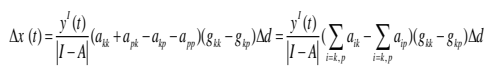

Thus, the impact of investment structure adjustment on the total output depends on the total investment level. The difference between $\sum_{i=k, p} a_{i k}$ and $\sum_{i=k, p} a_{i p}$, is just as well as the difference between $g_{k k}$ and $g_{k p}$. The difference between $\sum_{i=k, p} a_{i k}$ and $\sum_{i=k, p} a_{i p}$ reflects the difference between the amount output of total industries which is required for per unit of $k$ 's output industry industrial and per unit of other industries' output; And the difference between $g_{k k}$ and $g_{k p}$, reflects the difference of the output of $k$ and other sectors that per unit of capital formation of the $k$ industry or $\mathrm{k}$ industries will boost. These two differences reflect how the total output of the industry is affected by the adjustment of investment structure, and the importance and meaning of the complex interaction of various economic indicators in the inter-industry inputoutput system.

\section{Conclusion}

This article studied the effects of adjustment of investment structure on a country's economic performance, shows the endogenous effect mechanisms of the investment structural adjustment in the economic system.

The main results are as follows:

(1) The adjustment of investment structure will not change our current economic growth trends.

(2) The role of adjusting investment ratio on industry output, is jointly determined by the production direct consumption coefficient, investment direct consumption coefficient, which are relatively stable.

(3)Increasing investment in certain industries does not mean pull the output of the industry.

(4)Making investment decisions should take overall and long-term effects into account. We can not negative the effect of investment restructuring, just because it will lead to output falling in the industry or the industries.

\section{References}

[1] Liu Yu. Optimize the industrial structure of investment [J]. Cooperative Economy \& Science, pp.34-36, 2005

[2] Li Jie. The strategy options of investment industrial structure to catch up: International Experience and Implications. Social Science Research, pp.34-36,2002

[3] Fan Decheng, Liu Xisong. The dynamic input-output model [J]. China Management Science, pp.4245,2002

[4] Zhang Zhonghua. Investment (Second Edition) [M]. Higher Education Press,pp.169-177,2006

[5] Wang Yuqian, Yuan Jianwen, Li. The theory and method of input-Output Analysis[J]. Guangdong Higher Education Press,pp.21-24,2002 